\title{
Potencialidades hídricas superficiais de Fernando de Noronha, PE, e alternativas para incremento da oferta
}

\author{
Abelardo A. A. Montenegro ${ }^{1}$, Mateus R. Ribeiro', Suzana M. G. L. Montenegro², Marcus M. Corrêa ${ }^{1} \&$ Thais E. M. Santos ${ }^{3}$
}

RESUMO

A disponibilidade de recursos hídricos para usos múltiplos, com ênfase no abastecimento público, é questão da mais alta relevância e depende de aspectos edáficos, hidrológicos, ambientais e de gestão. Avaliou-se o potencial hídrico de bacias hidrográficas da Ilha de Fernando de N oronha, com vistas a dar suporte à gestão da água no arquipélago; para isto se delimitaram e caracterizaram cinco bacias representativas e se estimou a precipitação efetiva através do método da Curva Número. Adicionalmente, foram investigadas as características de infiltração dos principais solos do arquipélago. Verifica-se que, em geral, as bacias hidrográficas têm limitada infiltrabilidade e el evado potencial de escoamento, constatando-se o potencial de incremento de oferta de água superficial superior a 90\%, desde que se contemple a utilização racional das principais bacias existentes. Dentre os solos analisados, os Cambissolos Háplicos Vertissólicos e os Vertissolos são os solos de menor infiltrabilidade e, portanto, de maior contribuição à macrodrenagem do arquipélago. Sugere-se a utilização das bacias estudadas no abastecimento doméstico da Ilha, de modo a incrementar a disponibilidade de água no local.

Palavras-chave: ilha oceânica, método da curva-número, escoamento superficial

\section{Surface water availability in Fernando de Noronha, PE, and alternatives for supply increment}

\begin{abstract}
The availability of water resources for multiple uses, with emphasis an the public supply, is a very relevant task, which depends on soil, hydrological, environmental and management aspects. The water potential of the main basins of the Fernando de Noronha Island was evaluated, to support local water management. In this sense, five representative small basins of the area were delimited and characterized, and effective precipitation was estimated by the Curve Number Method. Additionally, the infiltration characteristics of the main soil types were investigated. It was verified that, in general, the local basins have high potential runoff and limited infiltrability, highlighting the local increase potencial of surface water higher than $90 \%$, if rational use of the main existing basins is implemented. Among the soils analysed the Vertic Haplic Cambisols and Vertisols are those with smaller infiltrability and, therefore, with larger contribution to the macrodrainage. The use of the studied basins is suggested in order to increase the water availability of island.
\end{abstract}

Key words: oceanic island, curve number method, runoff 


\section{INTRODUÇÃO}

Fernando de Noronha é um arquipélago isolado do Atlântico Equatorial, formado por uma ilha oceânica principal com o mesmo nome e por mais vinte ilhotas, totalizando uma área de $20 \mathrm{~km}^{2}$. A Ilha principal tem $17 \mathrm{~km}^{2}$, com cerca de $10 \mathrm{~km}$ de extensão e 3,5 km de largura máxima, com diversas elevações situadas na parte central e ocidental (SECTMA, 2006). Segundo Marques (2004), a Ilha de Fernando de Noronha é a única ilha oceânica brasileira constantemente habitada há mais de 500 anos, possuindo uma população flutuante de aproximadamente 2000 pessoas, motivadas, sobretudo pelo turismo ecológico.

Parte da Ilha é área do Parque Nacional Marinho desde 1988, havendo uma Área de Proteção Ambiental (APA) de 8 $\mathrm{km}^{2}$ e área do PARNAMAR, com $112,7 \mathrm{~km}^{2}$, incluindo-se a parte marítima (SECTMA, 2006).

Devido à grande demanda de água pela população e ao aumento no fluxo de turistas na ilha têm ocorrido, com frequência, limitações de abastecimento, com adoção de racionamentos, particularmente no verão.

O abastecimento é desenvolvido prioritariamente, a partir de fontes superficiais, em especial do açude do Xaréu, com reforços a partir do açude da Pedreira, além de poços profundos, nas fraturas. Salienta-se que a Ilha dispõe de outros mananciais os quais não vêm sendo explorados atualmente, devido a problemas de assoreamento.

Considerando as restrições de abastecimento já mencionadas, o Governo do Estado de Pernambuco investiu na dessalinização da água do mar, através de processo de osmose reversa. Tal sistema, além de requerer permanente manutenção, tem vazão limitada, insuficiente para atendimento da demanda local.

Uma alternativa a ser considerada é a reabilitação de açudes assoreados, de modo a incrementar a oferta hídrica, em conjunto com a indução da drenagem superficial nos solos menos permeáveis aumentando, assim, a captação da água de chuva e direcionando o escoamento para os açudes existentes.

Ribeiro et al. (2005) realizaram levantamento pedológico detalhado do arquipélago, tendo verificado que os solos dominantes nas principais bacias hidrográficas são os Cambissolos Háplicos, os Neossolos Litólicos e os Vertissolos.

A ilha não possui nascentes nem há cursos d'água perenes; deste modo, os escoamentos são gerados a partir da macrodrenagem de eventos pluviométricos relevantes. O Atlas de Recursos Hídricos do Estado de Pernambuco (SECTMA, 2006) destaca os seguintes riachos temporários: Riacho Mulungu, o Córrego de Atalaia, o Riacho do Boldró e o Riacho Maceió, o que alimenta o Açude do Xaréu. O potencial hidrológico das bacias contribuintes de tais açudes é fortemente influenciado pela infiltrabilidade dos solos.

Dentre as metodologias para estimativa de infiltração se destaca a equação de Green-Ampt. De acordo com Cecílio et al. (2003), o modelo de Green-Ampt é um dos que apresentam maior potencial de utilização, devido à sua fundamentação teórica, requerendo adequação de seus parâmetros a condições locais e a funcionais matemáticos.
Complementarmente, para avaliação do escoamento superficial causado por determinada chuva em bacias pequenas e com escassez de medições hidrológicas, o método proposto pelo Soil Conservation Service (SCS), denominado Método da Curva Número (CN), pode ser adotado; este método possibilita uma estimativa adequada do volume total escoado superficialmente, a partir de registros de precipitação total diária, permitindo a incorporação do efeito relativo da infiltrabilidade do solo (Souza et al., 1995). O Método $\mathrm{CN}$ foi aplicado, por exemplo, por Dufilho et al. (2001) para simular precipitações efetivas em bacias da Patagônia, Argentina, com carência de dados de precipitação e de hidrogramas, tendo produzido resultados satisfatórios.

Sartori et al. (2005) destacam que o método do SCS é um dos mais utilizados para estimativa de escoamento superficial. Os autores realizaram uma revisão detalhada da classificação hidrológica dos solos e enquadraram os principais solos brasileiros. Por exemplo, os Cambissolos de textura média e os Cambissolos Háplicos típicos foram enquadrados no Grupo Hidrológico C; os Vertissolos, Cambissolos vérticos e os Neossolos Litólicos, devido à limitada capacidade de infiltração, se situam no Grupo Hidrológico D. A classificação deste estudo é particularmente útil para estudos hidrológicos em Fernando de Noronha, tendo em vista a disponibilidade de mapeamento pedológico para o Arquipélago, como já comentado.

Este estudo objetiva avaliar o potencial hídrico das principais bacias hidrográficas da Ilha, investigando o comportamento hidrológico das principais unidades de solo, com vistas a oferecer suporte à gestão da água no arquipélago, e a embasar alternativas de incremento da oferta hídrica a partir da captação e armazenamento das águas de chuva.

\section{MATERIAL E MÉTODOS}

O clima da região do arquipélago é bastante influenciado pelas grandes massas de águas oceânicas, o que acaba refletindo no sistema hidrológico da ilha. Ocorrem duas estações bem definidas: uma úmida, que coincide com o período de março a maio, e outra seca, que ocorre de agosto a janeiro, caracterizando um clima do tipo Aw', de acordo com a classificação de Köppen (Marques et al., 2007a). A média histórica de 1992/2002, assim como a média anual dos anos de 2002 a 2004, mostra que abril é o mês do ano em que ocorre maior precipitação, acompanhado dos meses de março e maio; de setembro a dezembro quase não há ocorrência de chuvas. Conforme Marques (2004), o regime pluviométrico do Arquipélago é semelhante ao do Agreste Nordestino, devido principalmente às estações secas e chuvosas bem definidas e pela acentuada irregularidade de chuvas entre os anos.

Os solos da Ilha refletem, na sua gênese, influência do material de origem vulcânico, do relevo acidentado, do clima e da presença do oceano. Marques et al. (2007a) e Ribeiro et al. (2005) identificaram solos pouco evoluídos, pertencentes às classes dos Cambissolos, Vertissolos e Neossolos. Segundo Marques et al. (2007b), os Cambissolos Háplicos típicos se formam próximo aos divisores de água enquanto os Vertisso- 
los e Cambissolos Háplicos vérticos se localizam nas áreas de depressão topográfica, imperfeitamente a mal drenadas, apresentando textura muito argilosa, o que limita o processo de infiltração.

A Figura 1 apresenta as principais bacias da Ilha com destaque para os solos predominantes, segundo Ribeiro et al. (2005). Na Figura 2 tem-se, em destaque, a Bacia do Xaréu. Devido à limitada ocorrência dos Neossolos nas bacias de interesse, as análises de infiltrabilidade deste estudo se concentraram nas áreas de Vertissolos, de Cambissolo Háplicos típicos e de Cambissolo Háplicos vérticos.

Como se verifica nas Figuras 1 e 2, as principais unidades pedológicas na Bacia do Xaréu são os Vertissolos, os Cambissolos Háplicos típicos e os Cambissolos Háplicos vérticos. Composição semelhante ocorre na Bacia da Pedreira, notando-se a presença de Neossolos litólicos; já na Bacia do Borges os Vertissolos dão lugar a unidades de Neossolos litólicos. Nas bacias da Ema/ Boldró nota-se a ocorrência dos Cambissolos Háplicos vérticos e dos Vertissolos. Marques (2004) realizou descrição detalhada dos perfis dos solos predominantes. Os parâmetros físicos mais relevantes para este estudo estão apresentados na Tabela 1.

A Ilha é dotada de estação climatológica completa, operada pelo ITEP/ LAMEPE (Instituto Tecnológico do Estado de Pernambuco- Laboratório de Meteorologia), que fornece informações horárias de chuva, velocidade do vento, temperatura e umidade do ar. Para o ano de 2004, utilizado neste trabalho, o máximo valor de precipitação diária foi de 135,75 mm

Tabela 1. Características pedológicas dos solos predominantes de Fernando de Noronha

\begin{tabular}{|c|c|c|c|c|c|c|}
\hline Classificação & Areia & $\frac{\text { Silte }}{\left(\mathrm{g} \mathrm{kg}^{-1}\right)}$ & Argila & $\theta_{\text {sat }}$ & $\theta_{\mathrm{r}}$ & $\theta_{\mathrm{cc}}$ \\
\hline Vertissolo Cromado sódico gleico & 172 & 188 & 640 & 0,59 & 0,20 & 0,35 \\
\hline Cambissolo Háplico Eutroférrico típico & 300 & 274 & 426 & 0,66 & 0,22 & 0,28 \\
\hline Cambissolo Háplico Sódico vértico & 355 & 160 & 485 & 0,56 & 0,21 & 0,31 \\
\hline
\end{tabular}

Fonte: Marques (2004)

$\theta_{\text {sat }}$ - umidade na saturação $\left(\mathrm{cm}^{3} \mathrm{~cm}^{-3}\right) ; \theta_{\mathrm{r}}$ - umidade residual $\left(\mathrm{cm}^{3} \mathrm{~cm}^{-3}\right)$; $\theta_{\mathrm{cc}}$ - umidade na capacidade de campo $\left(\mathrm{cm}^{3} \mathrm{~cm}^{-3}\right)$

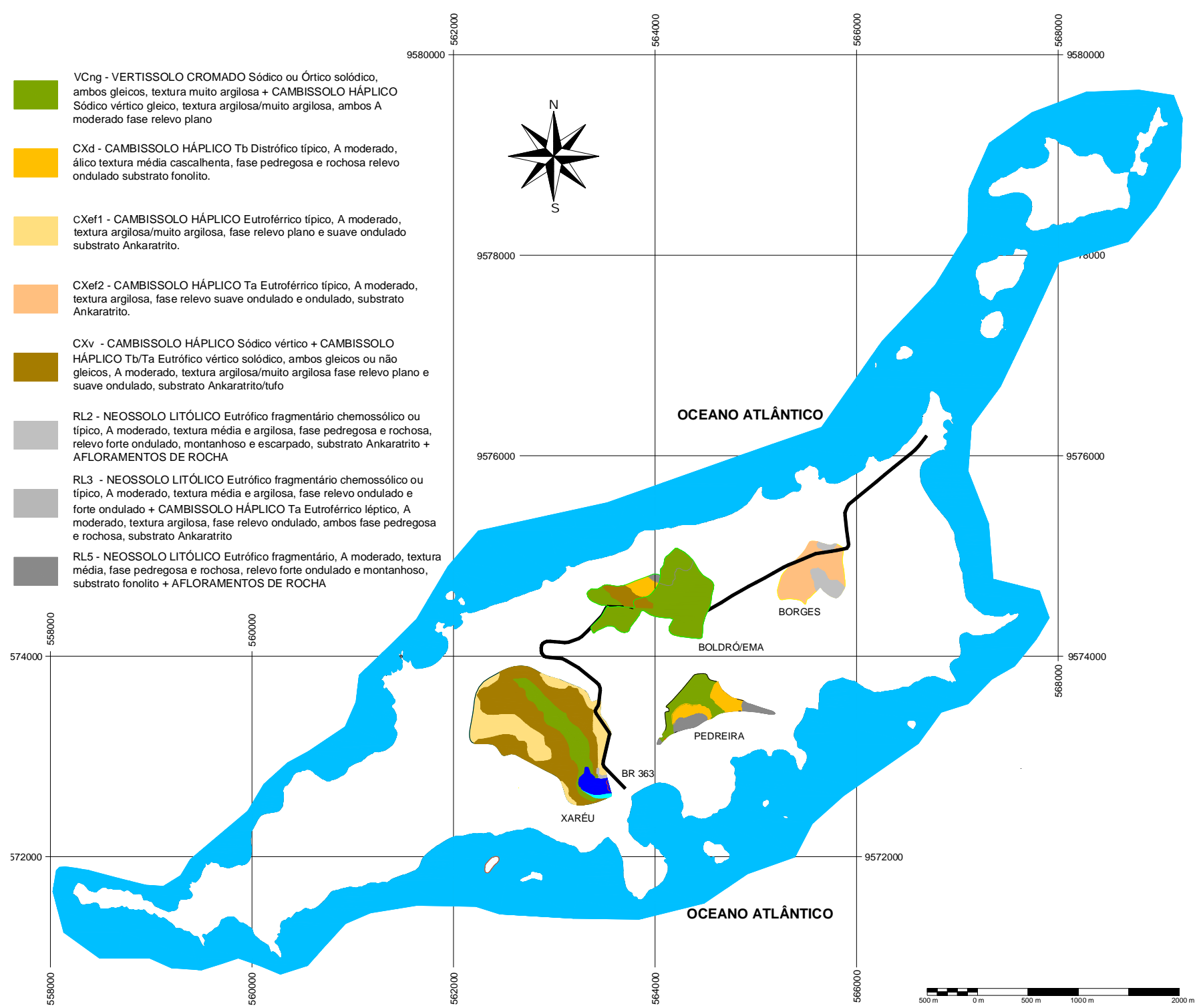

Figura 1. Principais bacias hidrográficas de Fernando de Noronha com destaque para os solos predominantes (Fonte: Adaptado de Ribeiro et al., 2005) 


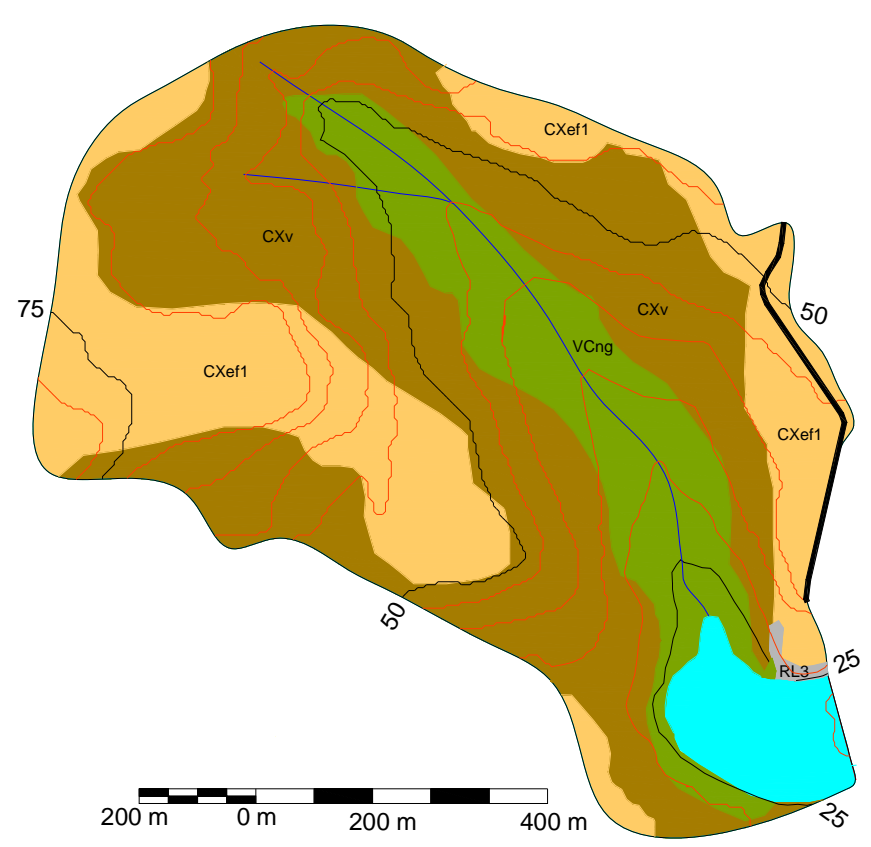

Figura 2. Bacia hidrográfica do Xaréu com destaque para as classes de solo predominantes (Fonte: Adaptado de Ribeiro et al., 2005)

e a precipitação total anual de 1351,5 mm. A Figura 3 apresenta as precipitações totais mensais considerando-se a Normal Climatológica e os valores médios do período de 1992 a 2006, além dos dados do ano de 2004.

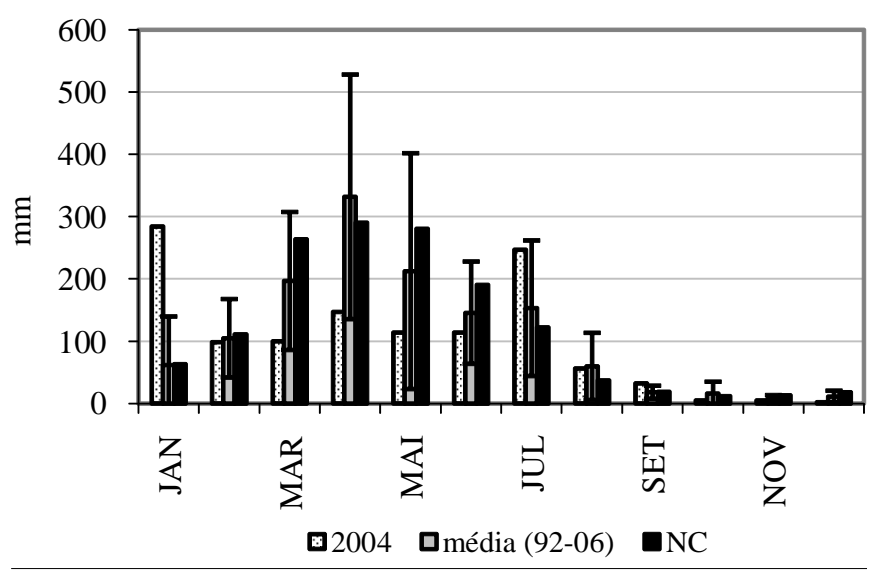

Figura 3. Precipitação total mensal em Fernando de N oronha: média do período de 1992 a 2006; dados do ano de 2004; e Normal Climatológica (NC)- barra representa o desvio-padrão

Eventos pluviométricos extremos foram analisados por Pfafstetter (1957), a partir de registros em pluviógrafos, havendo carência de estudos mais atuais sobre o comportamento das intensidades de precipitação na Ilha. Espera-se que, sempre que novos registros de intensidade sejam analisados, estudos complementares da pluviosidade possam ser desenvolvidos.

Utilizou-se, neste estudo, uma Carta Imagem com Hidrografia do Arquipélago de Fernando de Noronha, na escala 1:10000, com isolinhas topográficas de 5 em $5 \mathrm{~m}$, executada em julho de 2003, fornecida pela Secretaria de Ciência e Tecnologia do Meio Ambiente do Estado de Pernambuco, em que as bacias enfocadas foram: Xaréu, Pedreira, Ema, Boldró e Borges; a primeira bacia é a principal da Ilha, a partir da qual se realiza o abastecimento público pela concessionária de água do Estado (COMPESA), a Pedreira também é utilizada para fins de reforço no abastecimento; aqui ainda foram incluídas as bacias do Riacho da Ema e do Boldró e, nas proximidades da principal elevação topográfica, o Morro do Pico. $\mathrm{O}$ açude da bacia da Ema é usado exclusivamente para irrigação de pequeno porte a fim de suprir um perímetro de agricultura orgânica. À jusante da bacia da Ema se situa o açude do Boldró apresentando, atualmente, elevado grau de assoreamento; este açude possui localização estratégica nas proximidades da estação de tratamento de água da concessionária. $\mathrm{O}$ açude do Borges, próximo à Vila dos Remédios e com alto grau de impermeabilização, apresenta também elevado grau de assoreamento e não tem sido utilizado para abastecimento; tanto o Açude do Boldró quanto o do Borges já foram adotados no passado, para abastecimento.

Após estimativa da declividade das bacias e do comprimento de seus talvegues, utilizou-se o método de Kirpich, desenvolvido para bacias rurais de pequenas dimensões, com vistas ao cálculo de cada tempo de concentração.

De modo a se avaliar o potencial hidrológico das bacias hidrográficas, utilizou-se o Método da Curva Número (SCS USDA) considerando-se, para a obtenção da lâmina de escoamento superficial, dados de precipitação diária registrados na estação climatológica automática. Tendo em vista o predomínio de solos de textura argilosa na Ilha, de origem vulcânica, assumiu-se a condição tipo C, hipótese esta verificada adiante. A ocupação agrícola da bacia é regular podendo-se assumir boa drenabilidade. Segundo SCS (1972), o escoamento superficial no método da Curva Número, é estimado pela Eq. 1:

$$
\mathrm{ES}=\frac{(\mathrm{PT}-0,2 \mathrm{~S})^{2}}{(\mathrm{PT}+0,8)}
$$

em que:

ES é a lâmina de escoamento superficial; PT representa a precipitação total e $\mathrm{S}$ o armazenamento da bacia (valores em milímetros), estimado pela Eq. 2:

$$
\mathrm{S}=\frac{24500}{\mathrm{CN}}-254
$$

sendo CN a Curva Número.

Consideraram-se os dados de precipitação do ano de 2004, particularmente do período chuvoso, que se estende de abril a julho; os valores simulados foram comparados com os aportes volumétricos no açude do Xaréu, registrados em réguas linmétricas, monitoradas diariamente, no mesmo período.

Para o açude do Xaréu calibrou-se a Eq. 3 para a relação nível-volume:

$$
\mathrm{V}\left(1000 \mathrm{~m}^{3}\right)=78,997 \mathrm{e}^{0,2578 \mathrm{~N}(\mathrm{~m})} \quad \mathrm{r}^{2}=0,9985
$$

em que $\mathrm{N}$ é o nível do açude, em metros.

Objetivando-se avaliar o potencial da infiltração dos solos das bacias, estimou-se a condutividade hidráulica dos solos através de um Permeâmetro tipo Guelph, o qual permite 
a estimativa do parâmetro a (Eq. 7) da função K(y) (Eq. 6) proposta por Gardner (1958), a partir da medição da condutividade hidráulica saturada $\left(\mathrm{K}_{0}\right)$ de campo e do potencial de fluxo mátrico $\left(\mathrm{f}_{\mathrm{m}}\right)$; este dispositivo possibilita o monitoramento da taxa de infiltração em furo de sondagem, sob carga hidráulica constante. Quatro cargas foram adotadas, o que permite utilizar seis pares de cargas hidráulicas diferentes, sendo cada par de lâminas usado considerado repetição. As taxas de fluxo $\mathrm{Q}_{1}$ e $\mathrm{Q}_{2}$ são obtidas através da multiplicação das taxas de fluxo medidas por um coeficiente correspondente à razão das áreas do reservatório do dispositivo e do furo de sondagem. Os valores de condutividade hidráulica saturada são calculados segundo Reynolds \& Elrick (1986).

Segundo Reynolds \& Elrick (1986), a vazão no furo de sondagem pode ser descrita como apresenta a Eq. 4:

$$
2 \pi \mathrm{H}^{2} \mathrm{~K}_{0}+\mathrm{C} \pi \mathrm{a}^{2} \mathrm{~K}_{0}+2 \pi \mathrm{H} \phi_{\mathrm{m}}=\mathrm{CQ}
$$

em que:

$$
\begin{aligned}
& \text { a - é o raio do furo } \\
& \phi_{\mathrm{m}} \text { - é o potencial de fluxo matricial } \\
& \mathrm{H} \text { - é a carga hidráulica hidrostática no furo } \\
& \mathrm{K}_{0} \text { - é a condutividade hidráulica saturada de campo } \\
& \mathrm{C} \text { - é um parâmetro de ajuste dimensional } \\
& \mathrm{Q} \text { - é a vazão. }
\end{aligned}
$$

O termo $\phi_{\mathrm{m}}$ é definido pela Eq. 5:

$$
\phi_{\mathrm{m}}=\int_{\psi_{\mathrm{i}}}^{0} \mathrm{~K}(\psi) \mathrm{d} \psi
$$

$\mathrm{e}$

$$
\mathrm{K}(\psi)=\mathrm{K}_{0} \mathrm{e}^{\alpha_{\mathrm{G}} \psi}
$$

com:

$$
\alpha_{\mathrm{G}}=\frac{\mathrm{K}_{0}}{\phi_{\mathrm{m}}}
$$

sendo $\psi$ a tensão matricial do solo e $\alpha_{\mathrm{G}}$ um parâmetro de ajuste.

O Permeâmetro de Guelph possui várias vantagens, dentre elas a fácil montagem em campo. $\mathrm{O}$ ensaio, realizado com pequeno volume de água, permite a estimativa da curva de condutividade hidráulica não saturada e funciona, mesmo com pequenos gradientes hidráulicos junto à parede do furo. Os testes foram realizados na profundidade de $40 \mathrm{~cm}$, considerando-se a condição de perfis relativamente homogêneos na subsuperfície.

De modo a utilizar os testes de condutividade hidráulica com o permeâmetro para estimativa da curva característica e dos parâmetros físicos requeridos pelo modelo de Green-Ampt para a infiltração, ajustou-se o funcional de van Genuchten (1980) para condutividade hidráulica não saturada aos resultados experimentais dos testes de campo. Os funcionais de van Genuchten (1980) podem ser expressos segundo as Eqs. 8 e 9.

$$
\begin{gathered}
\mathrm{k}_{\mathrm{r}}(\psi)=\frac{\mathrm{K}(\psi)}{\mathrm{K}_{0}}=\frac{\left\{1-(\alpha \psi)^{\mathrm{n}-1}\left[1+(\alpha \psi)^{\mathrm{n}}\right]^{-\mathrm{m}}\right\}^{2}}{\left[1+(\alpha \psi)^{\mathrm{n}}\right]^{\mathrm{m} / 2}} \\
\frac{\theta-\theta_{\mathrm{r}}}{\theta_{\mathrm{s}}-\theta_{\mathrm{r}}}=\frac{1}{\left[1+(\alpha \psi)^{\mathrm{n}}\right]^{\mathrm{m}}}
\end{gathered}
$$

em que:

$\mathrm{K}(\psi)$ - condutividade hidráulica não saturada do solo

$\mathrm{K}_{0}$ - condutividade hidráulica saturada do solo

$\alpha$ - parâmetro de ajuste, $\mathrm{cm}^{-1}$

$\psi$ - tensão matricial do solo

m e $\mathrm{n}$ - parâmetros de ajuste da equação, adimensionais

$\theta-$ teor de água no solo, $\mathrm{cm}^{3} \mathrm{~cm}^{-3}$

$\theta \mathrm{s}$ - umidade de saturação, $\mathrm{cm}^{3} \mathrm{~cm}^{-3}$

$\theta \mathrm{r}$ - umidade residual, $\mathrm{cm}^{3} \mathrm{~cm}^{-3}$

De modo a avaliar o grau de concordância ou de ajuste entre o modelo de Gardner e o funcional de van Genuchten, calcularam-se o erro quadrático médio (EQM), a razão de desvios (RD) e a eficiência de modelagem (EM), com base nas Eqs. 10, 11 e 12, apresentadas por Antonino et al. (2001):

$$
\begin{gathered}
E Q M=\left[\frac{\sum_{i=1}^{N}\left(T_{i}-M_{i}\right)^{2}}{N}\right]^{\frac{1}{2}} \cdot \frac{100}{\bar{M}} \\
R D=\frac{\sum_{i=1}^{N}\left(M_{i}-\bar{M}\right)^{2}}{\sum_{i=1}^{N}\left(T_{i}-\bar{M}\right)^{2}} \\
E M=\frac{\sum_{i=1}^{N}\left(M_{i}-\bar{M}\right)^{2}-\sum_{i=1}^{N}\left(T_{i}-M_{i}\right)^{2}}{\sum_{i=1}^{N}\left(M_{i}-\bar{M}\right)^{2}}
\end{gathered}
$$

em que $T_{i}$ são os valores teóricos, $M_{i}$ são os valores medidos, M representa a média das medições e $\mathrm{N}$ o número de medições

Para análise do potencial de infiltração (Eq. 13) dos solos após estimativa dos parâmetros, utilizou-se o modelo de Green-Ampt, expresso por:

$$
\mathrm{K}_{\mathrm{s}} \mathrm{t}=\mathrm{F}-\mathrm{H}_{\mathrm{f}} \mathrm{n}_{\mathrm{a}} \ln \left(1+\frac{\mathrm{F}}{\mathrm{H}_{\mathrm{f}} \mathrm{n}_{\mathrm{a}}}\right)
$$

em que $\mathrm{K}_{\mathrm{s}}$ é a condutividade hidráulica saturada efetiva, tomada como metade da condutividade hidráulica de campo (Cecílio et al., 2003), $\mathrm{H}_{\mathrm{f}}$ a tensão na frente de umedecimento $(\mathrm{kPa}), \mathrm{n}_{\mathrm{a}}$ a porosidade disponível e F é a lâmina total infiltrada $(\mathrm{cm})$ durante um intervalo de tempo de ocorrência de uma precipitação P. O processo de escoamento superficial se inicia com o encharcamento do solo. A lâmina total infiltrada até a ocorrência do encharcamento a qual depende, dentre outros fatores, do estado de umidade antecedente do solo, pode ser estimada pela Eq. 14:

$$
\mathrm{F}_{\mathrm{P}}=\frac{\mathrm{H}_{\mathrm{f}} \mathrm{n}_{\mathrm{a}}}{\frac{\mathrm{P}}{\mathrm{K}_{\mathrm{S}}}-1}
$$


$\operatorname{com} \mathrm{n}_{\mathrm{a}}=\theta_{\text {ef }}-\theta_{\text {in }}$ em que $\theta_{\text {ef }}$ representa a porosidade efetiva e $\theta_{\text {in }}$ a umidade inicial ou antecedente.

Adotou-se, para estimativa da tensão matricial na frente de molhamento, a equação utilizada por Brakensiek (1977) e desenvolvida por Morel-Seytoux \& Khanji (1974), expressa pela Eq. 15:

$$
\mathrm{H}_{\mathrm{f}}=\int_{0}^{\psi\left(\theta_{\mathrm{i}}\right)} \mathrm{k}_{\mathrm{r}} \mathrm{d} \psi
$$

que representa a área abaixo da curva tensão x condutividade hidráulica relativa. Neste estudo se utilizou a curva produzida a partir de cada teste de condutividade com o permeâmetro de Guelph.

Para estimativa da infiltração, chuvas intensas de $1 \mathrm{~h}$ de duração na Ilha foram adotadas, segundo Pfafstetter (1957), e para tempos de retorno de 5, 8 e 10 anos. Durações adicionais foram consideradas após estimativa do tempo de concentração das bacias, conforme apresentado adiante. Salienta-se que com a adoção do tempo de concentração, bem como das distintas durações de chuva, objetivou-se realizar uma análise de sensibilidade para a geração dos escoamentos justificada em razão das reduzidas dimensões da bacia e, particularmente, por não se dispor ainda de um hidrograma de resposta avaliado em condições de campo.

Os escoamentos simulados para os meses de abril, maio e julho de 2004 nas bacias, se basearam apenas no Método da Curva Número uma vez que não foram registradas as intensidades de chuva para os citados períodos não permitindo, então, uma utilização adequada do Método de Green-Ampt para cálculo das lâminas de escoamento superficial diárias e comparação com os valores medidos, assim como para comparação direta entre os dois métodos.

\section{RESULTADOS E DISCUSSÃO}

\section{Análise de volumes escoados pelo método do SCS}

Apresentam-se, na Tabela 2, os principais parâmetros físicos das bacias hidrográficas de Fernando de Noronha, podendo-se verificar suas reduzidas dimensões e baixos tempos de concentração.

Tabela 2. Parâmetros físicos das Bacias de Fernando de Noronha*

\begin{tabular}{lcccc}
\hline \multicolumn{1}{c}{ Bacias } & $\mathbf{L}(\mathbf{k m})$ & $\mathbf{S}\left(\mathbf{m ~ k m} \mathbf{~}^{-1}\right)$ & $\mathbf{t c}(\mathbf{m i n})$ & Área $\left.\mathbf{( k m}^{\mathbf{2}}\right)$ \\
Xaréu & 1,30 & 34,61 & 17,82 & 1,16 \\
Ema & 0,75 & 22,66 & 13,74 & 0,42 \\
Pedreira & 0,85 & 17,65 & 16,65 & 0,24 \\
Boldró & 0,35 & 51,43 & 5,57 & 0,11 \\
Borges & 0,30 & 208,33 & 2,89 & 0,27 \\
\hline
\end{tabular}

* - $\mathrm{t}_{\mathrm{c}}$ - tempo de concentração, em min; L - comprimento do curso d’água, em km; S - declividade, em m km

A Bacia do Xaréu é a que apresenta maior comprimento do talvegue principal e maior área de captação possuindo, assim, um potencial hídrico maior.
Considerando-se a ocorrência nas bacias de solos classificados nos Grupos Hidrológicos C e D, segundo Sartori et al. (2005) e se tomando por base as Curvas Número para o complexo solo-cobertura segundo o SCS (1972), conclui-se que o $\mathrm{CN}$ para as bacias poderia ser assumido entre 70 e 76 para condições de infiltração regular.

A Tabela 3 apresenta a compilação das informações pedológicas apresentadas por Marques (2004), considerando-se o percentual dos solos nas principais bacias da Ilha.

Tabela 3. Percentual de tipo de solo por bacia hidrográfica, em Fernando de Noronha, PE

\begin{tabular}{lcccccc}
\hline \multicolumn{1}{c}{ Tipo de solo } & Xaréu & Borges & Pedreira & Ema & Boldró \\
Cambissolo Háplico eutroférrico típico & 30,0 & 78,1 & 21,0 & 19,2 & 31,3 \\
Cambissolo Háplico sódico vértico & 51,6 & - & 55,8 & 26,3 & 32,3 \\
Vertissolo Cromado sódico gleico & 18,4 & - & - & 6,3 & 31,3 \\
Neossolo Litólico Eutrófico fragmentário & - & 21,9 & 23,2 & 48,2 & 5,1 \\
\hline
\end{tabular}

Com base na comparação entre valores diários simulados e medições de aportes ao açude do Xaréu, no período monitorado, verificou-se que o valor de $\mathrm{CN}$ se situa, na realidade, entre 70 e 75, estando apresentando-se, nas Figuras 4A, B e $\mathrm{C}$, os valores de descarga para os meses de abril, maio e julho de 2004.

Mesmo levando em conta as variações pedológicas entre as bacias verifica-se que, em termos de Grupos Hidrológicos, há equilíbrio entre os Grupos $\mathrm{C}$ e $\mathrm{D}$, e as condições de infiltração são semelhantes entre as bacias, conforme a Tabela 3; deste modo e se adotando os valores 70, 72,50 e 75 para $\mathrm{CN}$, foram estimadas as descargas médias nas outras bacias e calculado o desvio-padrão desses escoamentos, como mostra a Figura 5.

\section{Infiltrabilidade dos solos dominantes}

Os resultados dos testes de Guelph estão apresentados na Tabela 4 enquanto os ajustes aos funcionais de Genuchten (1980) se encontram na Figura 6, para os principais solos da Ilha.

Tabela 4. Parâmetros do funcional de Gardner para a condutividade hidráulica, para o Vertissolo, Cambissolo Eutoférrico, e Cambissolo Háplico, de Fernando de Noronha, PE

\begin{tabular}{lcc}
\hline \multicolumn{1}{c}{ Classificação } & $\mathbf{K}_{0}\left(\mathbf{m m ~ h}^{-1}\right)$ & $\alpha_{\mathrm{G}}\left(\mathbf{k P a}^{-1}\right)$ \\
Vertissolo Cromado Sódico gleico & 2,88 & 0,156 \\
Cambissolo Háplico Eutroférrico típico & 5,76 & 0,387 \\
Cambissolo Háplico Sódico vértico & 4,32 & 0,184 \\
\hline
\end{tabular}

Tomando-se por base os resultados dos testes experimentais com o permeâmetro de Guelph e se adotando o funcional de Gardner (GR) (Eq. 6), ajustaram-se os parâmetros dos funcionais de Genuchten (VG) para a condutividade hidráulica (Eq. 8) utilizando-se o software Statistica (2001) (Tabela 5).

$\mathrm{O}$ valor de $\mathrm{a}_{\mathrm{VG}}$ encontrado para o Cambissolo vértico de Fernando de Noronha se aproxima do de Mello et al. (2005) 
A.
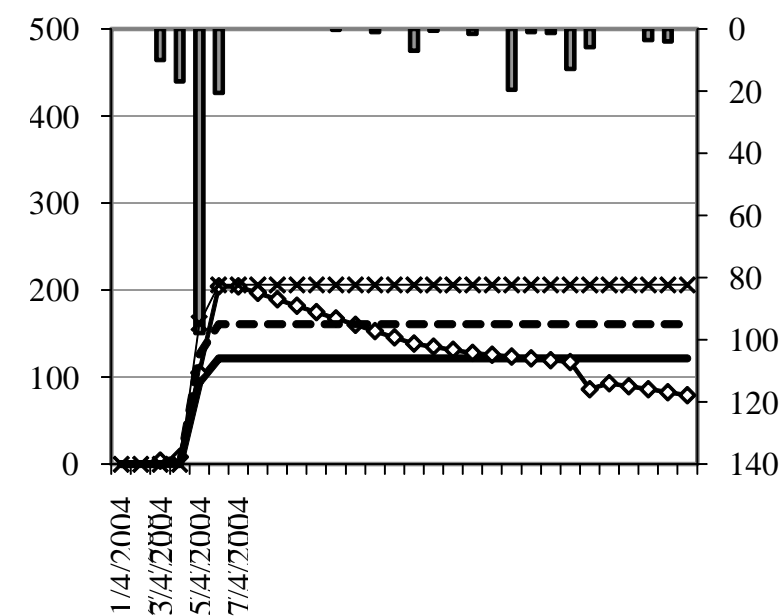

B.

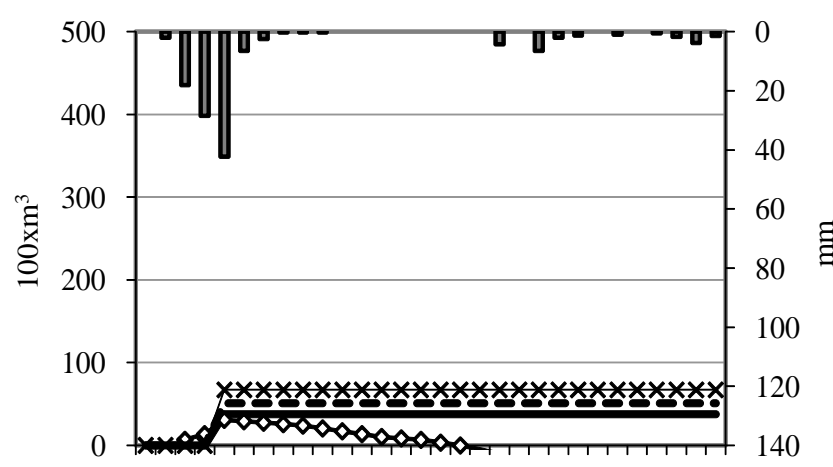

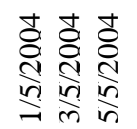

C.

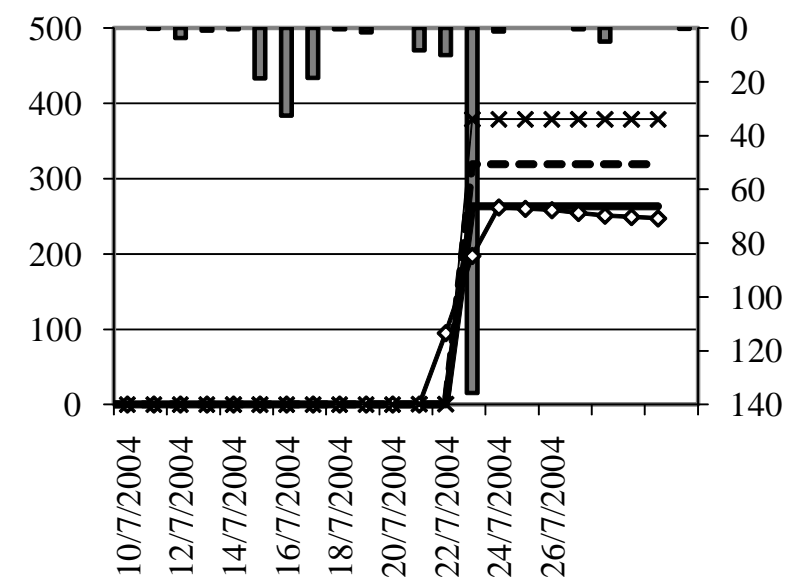

Figura 4. Valores medidos e simulados do escoamento na bacia do Xaréu, para os meses de abril (A), maio (B) e julho (C) de 2004

Tabela 5. Parâmetros estimados para os funcionais de van Genuchten, para os solos Vertissolo sódico, Cambissolo típico e Cambissolo sódico

\begin{tabular}{lllllll}
\hline \multicolumn{1}{c}{ Classificação } & nVG & $\boldsymbol{\alpha}\left(\mathbf{k P a}^{-1}\right)$ & $\mathbf{E Q M}(\%)$ & $\mathbf{R D}$ & $\mathbf{E M}$ & $\boldsymbol{\theta}^{*} \mathrm{cc}$ \\
Vertissolo Cromado sódico gleico & 2,10 & 0,067 & 0,12 & 0,91 & 0,99 & 0,36 \\
Cambissolo Háplico eutroférrico típico & 3,00 & 0,145 & 1,07 & 0,71 & 0,83 & 0,23 \\
Cambissolo Háplico sódico vértico & 2,10 & 0,070 & 0,18 & 0,89 & 0,99 & 0,34 \\
\hline $\mathrm{q}^{*}-$ valor estimado
\end{tabular}
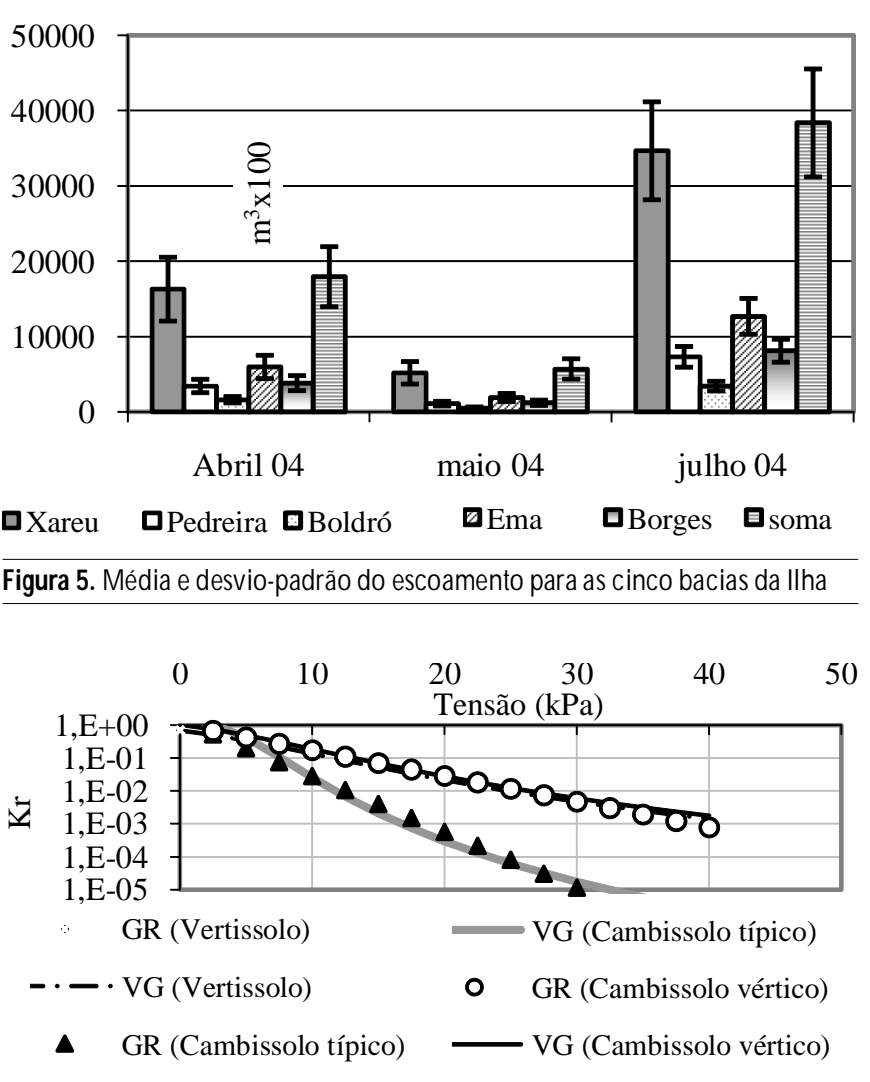

Figura 6. Condutividade hidráulica relativa em função da tensão matricial, para o Vertissolo Cromado sódico gleico, Cambissolo Háplico eutoférrico típico, e Cambissolo Háplico sódico vértico

para um Cambissolo originado de Gnaisse, em Minas Gerais; entretanto, os valores de $\mathrm{N}_{\mathrm{VG}}$ obtidos são superiores aos estimados por Mello et al. (2005). Salienta-se que os referidos Cambissolos de Gnaisse apresentam teores de argila sensivelmente inferiores aos vulcânicos de Fernando de Noronha; por outro lado e se comparando as Tabelas 1 e 4, verifica-se que as estimativas das umidades na capacidade de campo, utilizando-se o funcional de van Genuchten (equação 9) estão de acordo com as avaliações de laboratório efetuadas por Marques (2004). O valor de $\mathrm{a}_{\mathrm{VG}}$ para o Cambissolo vértico da Tabela 4 é similar ao encontrado por Antonino et al. (2001) para Neossolo Flúvico argiloso $\left(0,042 \mathrm{kPa}^{-1}\right)$, com teores de areia e de argila de 38 e $41 \%$, respectivamente, mas o valor de $\mathrm{N}_{\mathrm{VG}}$ para o Neossolo equivale a aproximadamente 50\% do encontrado para o Cambissolo sódico. Segundo Antonino et al. (2001) os funcionais de van Genuchten possibilitam estimativas adequadas de infiltração e de curva característica, em solos de textura argilosa.

Estimativas de Hf a partir da (Eq.15) estão apresentadas na Figura 6, variando em função da umidade inicial do solo. Esses valores contrastam levemente com os sugeridos por Rawls \& Brakensiek (1983), para solos de textura similar, com valores médios de 11,50 e $80 \mathrm{~cm}$, para o Vertissolo, Cambissolo típico e Cambissolo vértico, segundo textura apresentada na Tabela 1, por sua vez, os valores médios correspondentes à faixa de umidade entre 0,20 e $0,65 \mathrm{~cm}^{3} \mathrm{~cm}^{-3}$ (Figura 7) são de 55,40 e $55 \mathrm{~cm}$, respectivamente, para o Vertissolo, Cambissolo típico e Cambissolo vértico. 


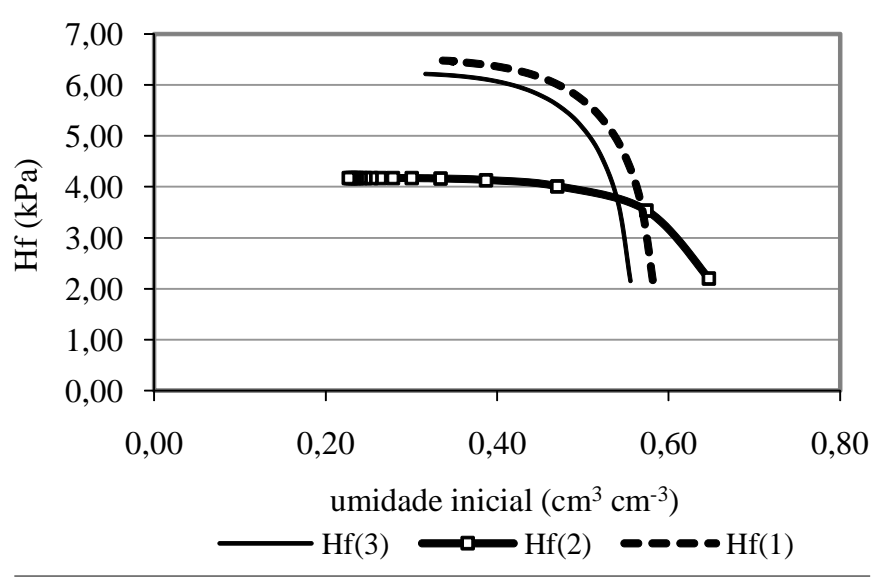

Figura 7. Tensão na frente de molhamento em função da umidade inicial, nos três principais solos da Iha: (1)-Vertissolo vértico; (2)-Cambissolo típico; (3)Cambissolo sódico

A.

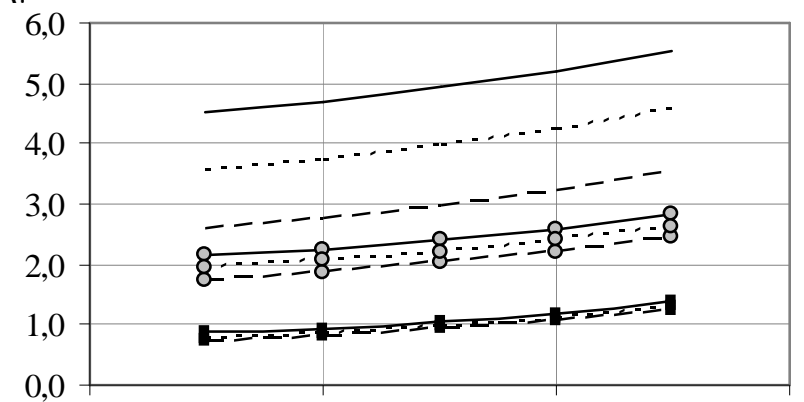

B.

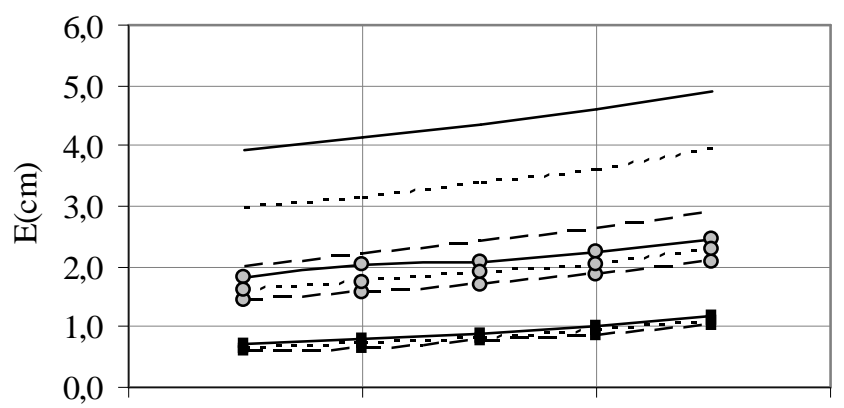

C.

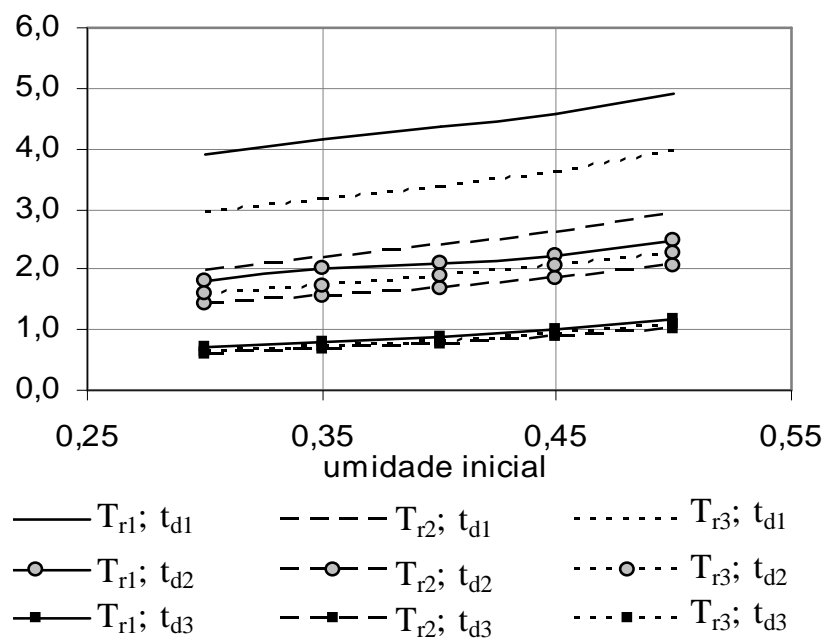

Figura 8. Lâminas de escoamento (E), em função da umidade inicial para 0 Vertissolo vértico (A), Cambissolo Háplico (B) e para o Cambissolo Háplico vértico $(C)$, respectivamente. Valores de $T_{r}$ de 10, 5 e 8 anos; $t_{d}$ de 1 h, 30 min e $15 \mathrm{~min}$, respectivamente
As Figuras 8A a 8C apresentam as lâminas de escoamento superficiais geradas nos solos da bacia, em função da umidade volumétrica inicial. Além de chuvas intensas de duração de $1 \mathrm{~h}$ foram consideradas, também, as durações de 15 e 30 min, de ordem de grandeza similar aos tempos de concentração estimados (Tabela 2). Os Cambissolos típicos geraram menor escoamento para as intensidades consideradas.

Quando se analisam, conjuntamente, os Grupos Hidrológicos dos solos, propostos por Sartori et al. (2001) e verificados neste estudo para os solos de Fernando de Noronha, nota-se que as faixas de infiltrabilidade sugeridas por aqueles autores são similares às encontradas aqui, igualmente, as condutividades hidráulicas saturadas medidas para as unidades pedológicas se aproximam daquelas sugeridas por Morel-Seytoux \& Khanji (1974), com efeito, para CN entre 70 e 75, Morel-Seytoux \& Khanji (1974) sugere uma faixa de condutividade hidráulica entre 4,013 e 2,057 $\mathrm{mm} \mathrm{h}^{-1}$.

\section{CONCLUSÕES}

1. O modelo da Curva-Número representou adequadamente a geração de deflúvios diários na Bacia do Xaréu, no ano de 2004, para um valor de CN situado entre 70 e 75 .

2. Verifica-se que, conjuntamente, as bacias da Pedreira, Boldró, Ema e Borges, têm potencial de gerar deflúvios equivalentes àqueles produzidos pela Bacia do Xaréu.

3. Sugere-se a utilização das bacias supracitadas no abastecimento doméstico da ilha, de modo a incrementar a disponibilidade de água no local.

4. Verifica-se, com base na análise de infiltrabilidade dos solos, que os Vertissolos e os Cambissolos Vérticos têm elevado potencial para gerar deflúvios superficiais.

\section{AGRADECIMENTOS}

À Administração da Ilha de Fernando de Noronha; à SECTMA- Secretaria de Ciência Tecnologia e Meio Ambiente do Estado de Pernambuco; à COMPESA e ao CNPq/CT-HIDRO, pelo apoio ao estudo em tela.

\section{LITERATURA CITADA}

Antonino, A. C. D.; Jaramillo, R. A.; Souza, E. S.; Netto, A. M.; Carneiro, C. J. G.; Montenegro, A. A. A. Determinação da condutividade hidráulica e da sorvidade de um solo com infiltrômetro a disco. Revista Brasileira de Engenharia Agrícola e Ambiental, v.5, n.2, p.247-253, 2001.

Brakensiek, D. L. Estimating the effective capillary pressure in the Green and Ampt infiltration equation. Water Resources Research, v.13, n.3, p.680-682, 1977.

Cecílio, R. A.; Silva, D. D.; Pruski, F. F.; Martinez, M. A. Modelagem da infiltração de água no solo sob condições de estratificação utilizando-se a equação de Green-Ampt. Revista Brasileira de engenharia Agrícola e Ambiental, v.7, n.3, p.415422, 2003. 
Dufilho, A. C.; Horne, F.; Navedo, R.; Polla, G. Diseño de obras de control de aluviones basada em simulación de procesos hidrológicos torrenciales em cuencas de la Patagônia. Revista Brasileira de Engenharia Agrícola e Ambiental, v.5, n.2, p.198203, 2001.

Gardner, W. R. Some steady state solutions of the unsaturated moisture flow equation with application to evaporation from water table. Soil Science, v.85, n.2, p.228-232, 1958.

Marques, F. A. Caracterização e classificação de solos da ilha de Fernando de Noronha (PE). Recife: UFRPE, 2004. 101p. Dissertação Mestrado

Marques, F. A.; Ribeiro, M. R.; Bittar, S. M. B.; Lima Neto, J. A.; Lima, J. F. N. F. Caracterização e classificação de Cambissolos do arquipélago de Fernando de Noronha, Pernambuco. Revista Brasileira de Ciência do Solo, v.31, n.5, p.1023-1034, 2007b.

Marques, F. A.; Ribeiro, M. R.; Bittar, S. M. B.; Tavares Filho, A. N.; Lima, J. F. W. F. Caracterização e classificação de Neossolos da ilha de Fernando de Noronha (PE). Revista Brasileira de Ciência do Solo, v.31, n.6, p.1553-1562, 2007a.

Mello, C. R.; Oliveira, G. C.; Ferreira, D. F.; Lima, J. M.; Lopes, D. Modelos para determinação da equação de van Genuchten para um Cambissolo, Revista Brasileira de Engenharia Agrícola e Ambiental, v.9, n.1, p.23-29, 2005.

Morel-Seytoux, H. J.; Khanji, J. Derivation of an equation of infiltration. Water Resource Research, v.10, n.4, p.795-800. 1974.

Pfafstetter, O. Chuvas intensas no Brasil. Rio de Janeiro: DNOS, 1957. 419p.

Rawls, W. J.; Brakensiek, D. L. A procedure to predict green and ampt infiltration parameters. In: Advances in Infiltration. St. Joseph: ASCE., 1983. 11p.
Reynolds, W. D.; Elrick, A. Method for simultaneous in situ measurement in the vadose zone of field saturated hydraulic conductivity, sorptivity and conductivity - pressure head relationship. Ground Water Monitoring Review, v.6, p.84-95, 1986.

Ribeiro, M. R.; Marques, F. A.; Bittar, S. M. B.; Ferraz, F. B.; Jacomine, P. K. T.; Lima, J. F. W. F. Caracterização e classificação dos solos do Arquipélago de Fernando de Noronha. In: Congresso Brasileiro de Ciência do Solo, 30, 2005, Recife. Anais...Recife: SBCS, 2005. CD-Rom.

Sartori, A.; Lombardi Neto, F.; Genovez, A. M. Classificação hidrológica de solos brasileiros para a estimativa da chuva excedente com o método do serviço de conservação do solo dos Estados Unidos. Parte 1: Classificação. Revista Brasileira de Recursos Hídricos, v.10, n.4, p.05-18, 2005.

SCS - Soil Conservation Service. Hydrology. In: National engineering handbook. Section 4. Washington: USDA, 1972. p.101- 1023.

SECTMA - Secretaria de Ciência Tecnologia e Meio Ambiente. Atlas de bacias hidrográficas de Pernambuco. Recife: SECTMA, 2006. 104p.

Souza, J. L.; Lombardi Neto, F.; Tubelis, A. Estimativa e análise do escoamento superficial em solo descoberto e cultivado com a sucessão soja e trigo, sob diferentes sistemas de manejo. Revista Brasileira de Agrometeorologia, v.3, p.77-84, 1995.

Statsoft. Statistica: Data analysis software system. Version 6. [S. L.], 2001

van Genuchten, M.Th. A closed-form equation for predcting the hydraulic conductivity of unsaturated soils. Soil Sciense Society America Journal, v.44, p.892-898, 1980. 